\title{
Finger lengths and behavior: Is the 2D:4D index of interest in forensic medicine?
}

\section{Anne Schwarz Walsted}

Unit of Forensic Anthropology, Institute of Forensic Medicine, University of Copenhagen. Frederik d. 5.'s Vej 11, DK-2100 Copenhagen

\begin{abstract}
The relationship between the second and the fourth digit in the human hand, the 2D:4D index, is considered a putative marker of exposure to prenatal testosterone. Much research has been done in the attempt to associate the 2D:4D index and physical characteristics as well as cognitive skills and behavioral patterns. It has been suggested that these characteristics and behavioral patterns may be linked to high levels of testosterone. The basis for considering the 2D:4D index a marker of prenatal exposure to testosterone, and the influence of prenatal and circulating testosterone on behavior are reviewed. Furthermore, it is discussed whether forensic medicine may benefit from identification of a marker of behavioral predispositions. It seems that it is not possible to derive any valid information on predispositions from finger length ratio, however the field of 2D:4D research might benefit from forensic studies.

Keywords:

2D:4D, digit length ratio, behavior, testosterone, forensic medicine
\end{abstract}

\section{INTRODUCTION}

The relationship between the length of the second and fourth digit has attracted some interest over the last years. Basically, it has been claimed that if the fourth digit is longer than the second digit, then the individual is more likely perform superiorly in sports [1] or be homosexual [2], while a longer second digit relative to the fourth predict neuroticism and increased risk of myocardial infarction [3]. The basic assumption is that the digit lengths correlate with testosterone exposure in utero and hence what may be termed testosteronebehavior [4]. In other words, it is suggested that high testosterone levels in utero predispose for such behavior in later life, and since skeletal growth is also affected by the testosterone level, the digit lengths thus become a marker for such behavior (or predisposition). There is evidence that the ratio of the length of the second and the fourth digit - 2D:4D - correlates significantly with the levels of testosterone an embryo has been exposed to in utero [5].

Research over the last decades has shown a pattern of effects of testosterone on human behavior [6]. Behavior influenced by high levels of testosterone may be characterized as violent or reckless and even fatal [7] From a forensic point of view 2D:4D as a marker or predictor of levels of circulating testosterone may be of interest. The impact of violent and/or reckless behavior is evident in clinical forensic medicine as well as in forensic pathology. The former, e.g., as perpetrators of violent crimes and the latter as individuals who are killed as a consequence of reckless driving or self-induced fatal incidents.

In this paper the 2D:4D ratio will initially be presented. Then the correlations between 2D:4D and testosterone as well as the correlations between testosterone and fatal behavior are reviewed. Finally, it is discussed whether 2D:4D might somehow be applicable in a forensic setting.

\section{Definition of the 2D:4D ratio}

2D:4D is measured simply with a caliper on the palmar surface of the right hand, from the most proximal crease (fourth digits often have two proximal creases) to the tip of the finger. The axis of symmetry in the human hand is the third digit, thus the second digit (2D) and the fourth digit (4D) of the symmetrical hand are of even length: 2D:4D $=1.00$.

\section{D:4D and testosterone}

Sex hormones are known not only to affect embryonic development of the gonadal system, but also the growth of digits of the extremities $[8,9]$, and lateralization [10]. Thus the effects of prenatal sex hormones are not only reflected by endocrine parameters such as sperm count, but are also seen in finger lengths and hemisphere dominance, e.g. handedness [8-11]. Prenatal androgens presumably induce asymmetry expressed as right-sided hemisphere dominance [10] and much research supports that they also are responsible for asymmetry in finger lengths [4]. A thorough scientometric analysis of the rather large body of literature on the subject in 2009 reaffirms the theory of the $2 \mathrm{D}: 4 \mathrm{D}$ ratio as a valid marker of exposure to prenatal testosterone [5].

\section{Normative values and correlations}

Much research has been done in attempt to link 2D:4D with certain physical traits, cognitive skills and behavioral patterns believed to be affected by prenatal and/or circulating testosterone. Sex dimorphism is demonstrated as early as in two-year-old children [8]. The general findings support that a $2 \mathrm{D}: 4 \mathrm{D}<1.00$ is considered a masculinized digit ratio, and $2 \mathrm{D}: 4 \mathrm{D} \geq 1.00$ is considered a feminized ratio. Normative masculine and feminine 2D:4D values may be estimated on an overview of mean ratios found in selected studies. The selected studies are considered representative because their study populations do not include individuals exposed to pathologically high concentrations of testosterone in utero, as is evident of $\mathrm{CAH}$-patients. 
Table 1. Mean values of male and female $2 \mathrm{D}: 4 \mathrm{D}$ ratios.

\begin{tabular}{|c|c|c|c|c|c|c|c|}
\hline Study & $\begin{array}{c}n \\
\text { (male; female) }\end{array}$ & Mean male ratio, right & Mean female ratio, right & $\mathrm{p}$ & Mean male ratio, left & Mean female ratio, left & p \\
\hline Manning, Scutt et al. 1998 & $400 ; 400$ & 0.980 & 1.000 & 0.0002 & 0.980 & 1.000 & 0.0002 \\
\hline Manning, Fink et al. 2006 & $497 ; 516$ & 0.987 & 1.000 & $<0.001$ & 0.981 & 0.995 & $<0.001$ \\
\hline Rizwan, Manning et al. 2007 & $262 ; 260$ & 0.967 & 0.978 & 0.0001 & 0.981 & 0.990 & 0.0001 \\
\hline Williams, Greenhalgh et al. 2003 & $108 ; 88$ & 0.947 & 0.961 & $<0.02$ & 0.950 & 0.963 & 0.01 \\
\hline Muller, Giles et al. 2011 & $1036 ; 620$ & 0.946 & 0.953 & $<0.001^{*}$ & 0.954 & 0.961 & $<0.001^{*}$ \\
\hline Putz et al. $2004^{* * *}$ & $220^{* *} ; 120$ & 0.949 & 0.974 & $<0.0001$ & 0.955 & 0.979 & $<0.0001$ \\
\hline
\end{tabular}

\footnotetext{
* significance tested using z-test by AS Poulsen

** male left hand $n 218$

*** no SD or SE for results reported
}

However, the findings are equivocal: homosexuality in males has been correlated to both low and high 2D:4D, and other studies have been found no significant correlation between 2D:4D and testicular function [27] adult levels of circulating sex hormones [14,19], and not all studies replicate sex dimorphism [20].

Further studies of associations between 2D:4D, testosterone and testosterone-associated behavior, and discussion of methodological issues and possibility of publication bias are found in reviews $[3,4,7,28]$

\section{Influence of testosterone on human behavior}

On a general level, secretion of testosterone is induced by confrontation with a challenge [6,29]. Extended research confirm that the level of circulating testosterone is positively correlated with secondary masculine characteristics such as a distinct jaw line, broad shoulders and relatively larger muscle mass compared to women [30]. In men, levels of circulating testosterone in significantly higher concentrations are found in violent criminal offenders, former soldiers who exhibit antisocial behavior, alcohol abusers and victims of suicide [29].

Other studies demonstrate that aggressive dominant behavior and sensation-seeking positively correlate with the level of circulating testosterone in both sexes -in other words: women with high levels of circulating testosterone tend to behave in a more masculine manner $[7,19,20,29,31,32]$.

Girls, who have been exposed to abnormally high concentrations of androgen in utero due to $\mathrm{CAH}$, tend to exhibit behavioral patterns more similar to boys in comparison with control groups of healthy girls $[17,31]$. The reason that these girls do not continue the development of secondary masculine characteristics in puberty is presumably because newborn girls with $\mathrm{CAH}$ are treated in order to reach subnormal to normal concentrations of androgen [31].

However, it is a major problem when analyzing these associations that there is no reliable method of measuring circulating testosterone level. Sperm counts or testosterone-concentration in saliva or serum have been used, however the secretion of testosterone is influenced by circadian variation and circumstantial variables such as the presence of a female researcher [33]
Table 2. Significant correlations with masculine and feminine 2D:4D ratios.

\begin{tabular}{|c|c|}
\hline Masculine $2 \mathrm{D}: 4 \mathrm{D}$ ratio & Study \\
\hline Left-handedness in males and females & $\begin{array}{c}\text { Jackson } 2008 \\
\text { Lust et al. } 2011 \\
\text { Manning \& Robinson } 2003 \\
\text { Putz et al } 2004\end{array}$ \\
\hline $\begin{array}{l}\text { Congenital adrenal hyperplasia (CAH) } \\
\text { in males and females }\end{array}$ & Brown et al. 2002 \\
\hline Homosexuality in females & McFadden et al. 2005 \\
\hline Homosexuality in males & Manning \& Robinson 2003 \\
\hline Penis size & Choi et al. 2011 \\
\hline Perceived dominance and masculinity & Neave et al. 2003 \\
\hline Aggression in females & Benderlioglu \& Nelson 2004 \\
\hline $\begin{array}{c}\text { Anti-social behavior in males and } \\
\text { females }\end{array}$ & Williams et al 2003 \\
\hline Visuo-spatial ability in females & Chai \& Jacobs 2012 \\
\hline $\begin{array}{l}\text { Superior fencing skills in males and } \\
\text { females }\end{array}$ & $\begin{array}{l}\text { Bescos et al. } 2009 \\
\text { Voracek et al. } 2006\end{array}$ \\
\hline Running speed in males and females & $\begin{array}{l}\text { Manning \& Hill } 2009 \\
\text { Manning et al. } 2007\end{array}$ \\
\hline Musical abilities in males & Putz et al. 2004 \\
\hline Traffic violations in males & Schwerdtfeger et al. 2010 \\
\hline Success in stock trading in males & Coates et al. 2009 \\
\hline \multicolumn{2}{|l|}{ Feminine $2 D: 4 D$ ratio } \\
\hline Homosexuality in males & McFadden et al. 2005 \\
\hline Low sperm count & Manning et al. 1998 \\
\hline
\end{tabular}

\section{D:4D as a proxy for testosterone associated behavior}

In lieu of the difficulties in obtaining precise measurements of testosterone levels 2D:4D is thus seen as a proxy. Among children, 2D:4D $<1.00$ has been associated with hyperactivity and lack of social skills $[13,34]$. This may be considered a predisposition, in the sense that the child is more sensitive to factors with negative influence on the development of social skills in adult life. As such, the prenatal androgen-level may constitute a predisposition of developing certain types of behavior, given the environmental factors that would contribute to e.g. a social deroute, including criminality. In this context, two studies of boys who have been exposed to maternal smoking 
in utero are worth mentioning. Nicotine inhibits the enzyme aromatase, which catalyze the conversion of androgen to estrogen; hence children of mothers who have smoked during pregnancy are exposed to higher levels of testosterone in utero than those of non-smoking mothers. Boys who have been exposed to prenatal maternal smoking have significantly lower 2D:4D ratio than boys of non-smoking mothers [12], just as they occur with a higher frequency in statistics of violent criminal offending, juvenile as well as persistent [35]. Associating these two findings should not be done uncritically, because it may rely partly on social confounding. However, the findings do support the idea of human behavior being influenced by biological as well as environmental factors.

\section{D:4D in a forensic context}

The above research does indicate that testosterone associated behavior may reflect prenatal exposure to testosterone, leading to the hypothesis that prenatal testosterone predisposes for a low threshold for stimulation of testosterone-production or an increased sensitivity to testosterone. There also seems to be an association between 2D:4D and in utero testosterone levels. Does this imply that 2D:4D might be of use as a marker for testosterone associated behavior? Perhaps especially in a forensic setting, where one might expect to see perpetrators as well as deaths associated with such behavior?
Presumably, this is not the case. Naively associating 2D:4D with specific behavior (in this case criminal behavior) carries a huge risk of committing the so-called prosecutor fallacy [36]. This fallacy is when frequencies of certain traits are combined to "prove" that a specific trait indicates or "proves" another trait. Bayes' theorem must be applied to correctly judge the conditional frequencies, but this relies on being able to reasonably know the various trait frequencies [36].

While the existing literature may point to a relationship between 2D:4D and testosterone associated behavior, and also supply a physiologically plausible explanation, 2D:4D cannot in any way be used as a predictor or as an incriminating trait. Neither should 2D:4D be used as an indicator of likeliness to re-offend or indicator of higher relative risk of dying due to death-defying behavior. In doing so, we would be reconnecting with Cesare Lombroso [37] who in the late $19^{\text {th }}$ century argued that certain physical traits including left-handedness (many of which are also testosterone associated, like a move massive facial skeleton or more facial hair) and even tattoos, were deemed highly indicative of the person being of a criminal nature.

This being said, we might use the research to extend our knowledge on heredity and environmental factors influencing psychopathology. Such a study could include data collected from post mortem measurements of finger lengths of all bodies brought to medico-legal autopsy combined with cause of death. The hypothesis would be that victims of suicide or violent (self-inflicted) causes would present a lower 2D:4D than those who died from other causes.

\section{REFERENCES}

[1] Bescos R, Esteve M, Porta J, Mateu M, Irurtia A, Voracek M. Prenatal programming of sporting success: associations of digit ratio (2D:4D), a putative marker for prenatal androgen action, with world rankings in female fencers. Journal of sports sciences. 2009 Apr;27(6):625-32. PubMed PMID: 19308788.

[2] Manning JT, Robinson SJ. 2nd to 4th digit ratio and a universal mean for prenatal testosterone in homosexual men. Medical hypotheses. 2003 Aug;61(2):303-6. PubMed PMID: 12888323.

[3] Putz DA, Gaulin SJC, Sporter RJ, McBurney DH. Sex hormones and finger length: What does 2D:4D indicate? Evolution and Human Behavior. 2004;25(3):182-99.

[4] Breedlove SM. Minireview: Organizational hypothesis: instances of the fingerpost. Endocrinology. 2010 Sep;151(9):4116-22. PubMed PMID: 20631003. Pubmed Central PMCID: 2940503.

[5] Voracek M, Loibl LM. Scientometric analysis and bibliography of digit ratio (2D:4D) research, 1998-2008. Psychological reports. 2009 Jun;104(3):922-56. PubMed PMID: 19708418.

[6] Archer J. Testosterone and human aggression: an evaluation of the challenge hypothesis. Neuroscience and biobehavioral reviews. 2006;30(3):319-45. PubMed PMID: 16483890. Epub 2006/02/18. eng.

[7] Giammanco M, Tabacchi G, Giammanco S, Di Majo D, La Guardia M. Testosterone and aggressiveness. Medical science monitor : international medical journal of experimental and clinical research. 2005 Apr;11(4):RA136-45. PubMed PMID 15795710. Epub 2005/03/30. eng.

[8] Manning JT, Scutt D, Wilson J, Lewis-Jones DI. The ratio of 2 nd to 4 th digit length a predictor of sperm numbers and concentrations of testosterone, luteinizing hormone and oestrogen. Human reproduction. 1998 Nov;13(11):3000-4. PubMed PMID: 9853845
[9] Mclntyre MH. The use of digit ratios as markers for perinatal androgen action. Reproductive biology and endocrinology : RB\&E. 2006;4:10. PubMed PMID: 16504142. Pubmed Central PMCID: PMC1409789. Epub 2006/03/01. eng.

[10] Jackson C. Prediction of hemispheric asymmetry as measured by handedness from digit length and 2D:4D digit ratio. Laterality. 2008 Jan;13(1):34-50. PubMed PMID: 18050000

[11] Manning JT, Fink B, Neave N, Szwed A. The second to fourth digit ratio and asymmetry. Annals of human biology. 2006 Jul-Aug;33(4):480-92. PubMed PMID: 17060070.

[12] Rizwan S, Manning JT, Brabin BJ. Maternal smoking during pregnancy and possible effects of in utero testosterone: evidence from the 2D:4D finger length ratio. Early human development. 2007 Feb;83(2):87-90. PubMed PMID: 16814493.

[13] Williams JH, Greenhalgh KD, Manning JT. Second to fourth finger ratio and possible precursors of developmental psychopathology in preschool children. Early human development. 2003 May;72(1):57-65. PubMed PMID: 12706312.

[14] Muller DC, Giles GG, Bassett J, Morris HA, Manning JT, Hopper JL, et al. Second to fourth digit ratio (2D:4D) and concentrations of circulating sex hormones in adulthood. Reproductive biology and endocrinology : RB\&E. 2011;9:57. PubMed PMID: 21521531. Pubmed Central PMCID: 3107785

[15] McFadden D, Loehlin JC, Breedlove SM, Lippa RA, Manning JT, Rahman Q. A reanalysis of five studies on sexual orientation and the relative length of the 2 nd and 4th fingers (the 2D:4D ratio). Archives of sexual behavior. 2005 Jun;34(3):34156. PubMed PMID: 15971017.

[16] Lust JM, Geuze RH, Van de Beek C, Cohen-Kettenis PT, Bouma A, Groothuis TG. Differential effects of prenatal testosterone on lateralization of handedness and language. Neuropsychology. 2011 Sep;25(5):581-9. PubMed PMID: 21500918. Epub 2011/04/20. eng. 
[17] Brown WM, Hines M, Fane BA, Breedlove SM. Masculinized finger length patterns in human males and females with congenital adrenal hyperplasia. Hormones and behavior. 2002 Dec;42(4):380-6. PubMed PMID: 12488105. Epub 2002/12/19. eng.

[18] Choi IH, Kim KH, Jung H, Yoon SJ, Kim SW, Kim TB. Second to fourth digit ratio: predictor of adult penile length. Asian journal of andrology. 2011 Sep;13(5):710-4 PubMed PMID: 21725330.

[19] Neave N, Laing S, Fink B, Manning JT. Second to fourth digit ratio, testosterone and perceived male dominance. Proceedings Biological sciences / The Royal Society. 2003 Oct 22;270(1529):2167-72. PubMed PMID: 14561281. Pubmed Central PMCID: 1691489.

[20] Benderlioglu Z, Nelson RJ. Digit length ratios predict reactive aggression in women, but not in men. Hormones and behavior. 2004 Dec;46(5):558-64. PubMed PMID: 15555497.

[21] Chai XJ, Jacobs LF. Digit ratio predicts sense of direction in women. PloS one. 2012;7(2):e32816. PubMed PMID: 22393451. Pubmed Central PMCID PMC3290629. Epub 2012/03/07. eng.

[22] Voracek M, Reimer B, Ertl C, Dressler SG. Digit ratio (2D:4D), lateral preferences, and performance in fencing. Perceptual and motor skills. 2006 Oct;103(2):427-46. PubMed PMID: 17165406

[23] Manning JT, Morris L, Caswell N. Endurance running and digit ratio (2D:4D): implications for fetal testosterone effects on running speed and vascular health American journal of human biology : the official journal of the Human Biology Council. 2007 May-Jun;19(3):416-21. PubMed PMID: 17420996.

[24] Manning JT, Hill MR. Digit ratio (2D:4D) and sprinting speed in boys. American journal of human biology : the official journal of the Human Biology Council. 2009 Mar-Apr;21(2):210-3. PubMed PMID: 19107924.

[25] Coates JM, Gurnell M, Rustichini A. Second-to-fourth digit ratio predicts success among high-frequency financial traders. Proceedings of the National Academy of Sciences of the United States of America. 2009 Jan 13;106(2):623-8. PubMed PMID: 19139402. Pubmed Central PMCID: 2626753.

[26] Schwerdtfeger A, Heims R, Heer J. Digit ratio (2D:4D) is associated with traffic violations for male frequent car drivers. Accident; analysis and prevention. 2010 Jan;42(1):269-74. PubMed PMID: 19887167.

[27] Bang AK, Carlsen E, Holm M, Petersen JH, Skakkebaek NE, Jorgensen N. A study of finger lengths, semen quality and sex hormones in 360 young men from the general Danish population. Human reproduction. 2005 Nov;20(11):3109-13. PubMed PMID: 16006470

[28] Yildirim BO, Derksen JJ. A review on the relationship between testosterone and life-course persistent antisocial behavior. Psychiatry research. 2012 Dec 30;200(23):984-1010. PubMed PMID: 22925371.

[29] Mazur A, Booth A. Testosterone and dominance in men. The Behavioral and brain sciences. 1998 Jun;21(3):353-63; discussion 63-97. PubMed PMID: 10097017. Epub 1999/03/31. eng.

[30] Koehler N, Simmons LW, Rhodes G. How well does second-to-fourthdigit ratio in hands correlate with other indications of masculinity in males? Proceedings Biological sciences / The Royal Society. 2004 Aug 7;271 Suppl 5:S296-8. PubMed PMID: 15503999. Pubmed Central PMCID: 1810055.

[31] Cohen-Bendahan CC, van de Beek C, Berenbaum SA. Prenatal sex hormone effects on child and adult sex-typed behavior: methods and findings. Neuroscience and biobehavioral reviews. 2005 Apr;29(2):353-84. PubMed PMID: 15811504. Epub 2005/04/07. eng

[32] Burnham TC. High-testosterone men reject low ultimatum game offers. Proceedings Biological sciences / The Royal Society. 2007 Sep 22;274(1623):232730. PubMed PMID: 17613451. Pubmed Central PMCID: PMC1950304. Epub 2007/07/07. eng.

[33] Honekopp J, Bartholdt L, Beier L, Liebert A. Second to fourth digit length ratio (2D:4D) and adult sex hormone levels: new data and a meta-analytic review. Psychoneuroendocrinology. 2007 May;32(4):313-21. PubMed PMID: 17400395.

[34] Collaer ML, Hines M. Human behavioral sex differences: a role for gonadal hormones during early development? Psychological bulletin. 1995 Jul;118(1):55107. PubMed PMID: 7644606. Epub 1995/07/01. eng.

[35] Brennan PA, Grekin ER, Mednick SA. Maternal smoking during pregnancy and adult male criminal outcomes. Archives of general psychiatry. 1999 Mar;56(3):2159. PubMed PMID: 10078497. Epub 1999/03/17. eng.

[36] Fenton N. Science and law: Improve statistics in court. Nature. 2011 Nov 3;479(7371):36-7. PubMed PMID: 22051660. Epub 2011/11/05. eng.

[37] Kushner HI. Deficit or creativity: Cesare Lombroso, Robert Hertz, and the meanings of left-handedness. Laterality. 2012 Jul 4. PubMed PMID: 22757625. Epub 2012/07/05. Eng. 